\title{
Interesting reactivity of diketones with pyrrole under acidic condition
}

\author{
SANJEEV PRAN MAHANTA and PRADEEPTA KUMAR PANDA* \\ School of Chemistry, University of Hyderabad, Gachibowli, P.O. Central University, Hyderabad 500 046, India \\ e-mail:pkpsc@uohyd.ernet.in; pradeepta.panda@gmail.com
}

MS received 18 October 2010; revised 7 June 2011; accepted 13 June 2011

\begin{abstract}
The acid catalysed condensation of diketones with pyrrole did not result in the formation of expected divergent bisdipyrromethane always; instead the product depends on the chain length of the diketones, in particular the distance between the two carbonyl functional groups. When the two carbonyl groups are linked via one or two methylene groups, unusual ring annulation occurs resulting in the formation of various bridged bipyrroles. However, on further increase in the length of the spacer, between the two carbonyl groups, synthesis of the expected bisdipyrromethanes could be achieved.
\end{abstract}

Keywords. Bisdipyrromethane; divergent bisdipyrromethane; tetrahydroindole-bridged bipyrrole; unusual ring annulations.

\section{Introduction}

Meso-functionalized dipyrromethanes (DPMs) are widely used as building blocks for the synthesis of porphyrins, corroles, calixphyrins and calixpyrroles; in particular, the strapped types which show enhanced anion binding abilities. ${ }^{1-3}$ The synthesis of mesosubstituted dipyrromethane (DPM) basically involves the acid-catalysed condensation of aldehyde or ketone with pyrrole or its derivatives. In the past two decades, the synthesis of meso-substituted DPMs has undergone several developments, the most important being the one-pot 'solventless' synthesis of DPM developed by Lindsay et al., ${ }^{4}$ which in general uses excess pyrrole that act both as a reagent and solvent and the subsequent modifications of this procedure, ${ }^{4}$ and the other one (developed more recently) being an environmentfriendly method which uses water as the solvent. ${ }^{5}$

While DPMs are useful in making various monomeric porphyrinoid macrocycles, development of dimeric and oligomeric porphyrins and calixpyrroles involve a lot of tedious processes. ${ }^{6}$ Although several bisdipyrromethanes (bisDPMs) were reported, they are of convergent type and useful for making strapped calixpyrroles. ${ }^{3}$ However, in order to make biscalixpyrroles, with an objective to observe cooperative anion binding, it is envisaged that divergent bisDPMs will be very good building blocks. So far, there are only two reports regarding the synthesis of this type of

*For correspondence
bisDPMs in one step from 1,4-cyclohexanedione and admantane derivatives. ${ }^{7}$ Towards developing the chemistry of bisDPM, recently we condensed acetylacetone (2,4-pentanedione) and pyrrole under acidic conditions to obtain 1 following the above two conditions (scheme 1).

To our surprise, an unexpected ring annulation, resulted in the formation of a bipyrrole moiety bridged via 2, 3-dihydro-1H-pyrrolizine through its 1,3 - position 2. ${ }^{8 a}$ Recently, we found the directly linked diketone 2,3-butanedione only produced the mesoacylatedDPM. ${ }^{8 \mathrm{~b}}$ Therefore, we have started exploring the reactivity of various diketones (carbonyl groups linked via different carbon chain), viz., 2,5hexanedione, 2,6-heptanedione, 2,8-nonanedione and

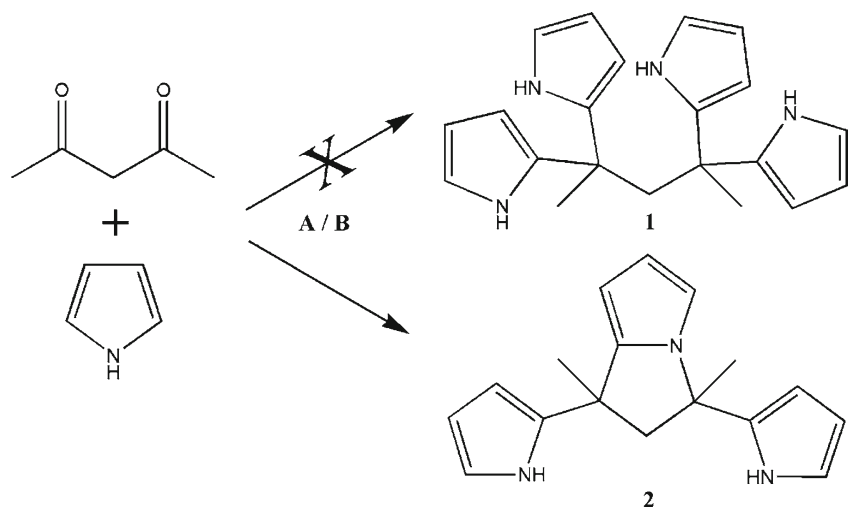

Scheme 1. Method A: acac (1 eq.), pyrrole (10 eq.), TFA (0.2 eq.), 5 min.; Method B: acac (1 eq.), pyrrole (4 eq.), $\mathrm{H}_{2} \mathrm{O}$, conc. $\mathrm{HCl}(0.2$ eq. $), 90^{\circ} \mathrm{C}, 45 \mathrm{~min}$. 


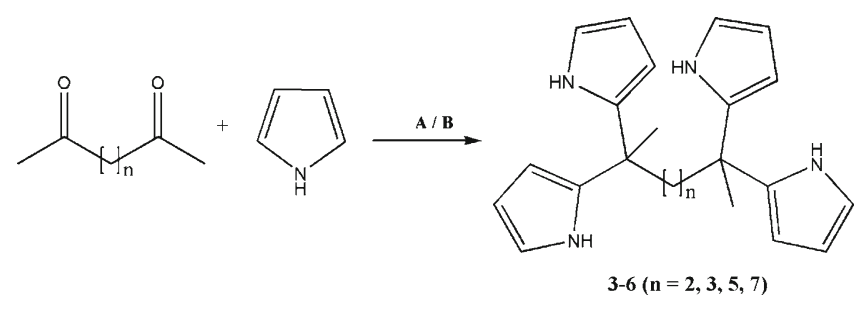

Scheme 2. Proposed reaction scheme.

2,10-undecanedione with pyrrole under acidic conditions. The objective was to see if the ring annulation occurred in case of $\mathbf{2}$, is due to the conjugated nature of the diketone, i.e., acetylacetone and also if at all we can achieve the target, i.e., divergent bisDPM (scheme 2).

Although many acid catalysts can be used for the desired transformations, we mainly focused on trifluoroacetic acid (TFA) as the formation of $\mathrm{N}$-confused derivative is minimal compared to $\mathrm{BF}_{3}$-etherate and hence purification will be easier (Method A). The second method, we considered is the $\mathrm{HCl}$ catalysed, aqueous method, owing to its environmentally benign nature and also it needs stoichiometric amount of pyrrole (Method B). We did not consider $\mathrm{InCl}_{3}$ as it is relatively more expensive and difficult to handle. Again it needs very large amount of pyrrole and tedious aqueous base work up in order to recycle the pyrrole.

\section{Experimental}

Pyrrole, trifluoroacetic acid, acetonylacetone (2,5hexanedione), were purchased from Aldrich. Pyrrole was distilled before use (not dried). 2,6-heptanedione, ${ }^{9}$ 2,8-nonanedione and 2,10-undecanedione ${ }^{10}$ were prepared following literature procedures. Chromatography was performed by using 100-200 mesh silica gel obtained from Merck. The new compounds synthesized were rigorously characterized via melting point, ${ }^{1} \mathrm{H}$ and ${ }^{13} \mathrm{C}$ NMR spectroscopy, mass and elemental analysis and wherever possible the solid state structures were elucidated using single crystal X-ray diffraction technique. Melting points were determined by open capillary tubes on a BIO-TECH, India apparatus. ${ }^{1} \mathrm{H}$ and ${ }^{13} \mathrm{C}$ NMR were obtained on a Bruker $400 \mathrm{MHz}$ FT NMR spectrometer. Mass spectral determinations were carried out by Shimadzu-LCMS-2010 mass spectrometer and elemental analyses were obtained through Thermo Finnigan Flash EA 1112 analyzer. Single crystal X-ray structures were elucidated by collecting reflections on a Bruker SMART CCD diffractometer. Mo- $\mathrm{K}_{\alpha}(\lambda=$ $0.71073 \AA$ ) radiation was used to collect the X-ray reflections of all the crystals. Data reduction was performed using Bruker SAINT software. Structures were solved and refined using SHELXL-97 with anisotropic displacement parameters for non-H atoms. HPLC was carried out by Shimadzu LC-20AT chromatogram with SPD detector using Daicel Chiralcel AS-H column.

\subsection{Synthesis of oligopyrrolic derivatives}

2.1a 4,7-Dimethyl-4,7-di(1H-pyrrol-2-yl)-4,5,6,7tetrahydro-1H-indole (7): Method - A: Pyrrole $(6.0 \mathrm{~mL}, 87.7 \mathrm{mmol})$ and hexane-2,5-dione $(500 \mathrm{mg}$, $4.4 \mathrm{mmol}$ ) were mixed together under $\mathrm{N}_{2}$ atmosphere, TFA $(72 \mu \mathrm{L}, 0.9 \mathrm{mmol})$ was added. The reaction mixture was stirred for $12 \mathrm{~h}$ at room temperature and was quenched by adding excess triethylamine. The excess pyrrole was removed by rotary evaporator under reduced pressure. The resultant mixture was purified by silica gel chromatography using $30 \%$ ethylacetatehexane as eluent. Evaporation of the eluent yields $620 \mathrm{mg}(50 \%)$ of white solid. One of the diastereomer of 7 was obtained by recrystallization from chloroformhexane in $44 \%$ yield as white solid, mp $206-208^{\circ} \mathrm{C} ;{ }^{1} \mathrm{H}$ NMR $\left(400 \mathrm{MHz}, \mathrm{CDCl}_{3}\right): \delta 7.88(\mathrm{~s}, 1 \mathrm{H}, \mathrm{NH}), 7.79(\mathrm{~s}$, $1 \mathrm{H}, \mathrm{NH}), 7.62(\mathrm{~s}, 1 \mathrm{H}, \mathrm{NH}), 6.75(\mathrm{t}, 1 \mathrm{H}, \mathrm{J}=2.8 \mathrm{~Hz})$, $6.60(\mathrm{~d}, 1 \mathrm{H}, \mathrm{J}=1.6 \mathrm{~Hz}), 6.55(\mathrm{~d}, 1 \mathrm{H}, \mathrm{J}=1.6 \mathrm{~Hz}), 6.15$ (m, 3H), $5.94(\mathrm{~m}, 2 \mathrm{H}), 1.91-1.75\left(\mathrm{~m}, 4 \mathrm{H}, \mathrm{CH}_{2}\right), 1.62$ (s, 6H, $\left.\mathrm{CH}_{3}\right) ;{ }^{13} \mathrm{C}$ NMR (400 MHz, $\mathrm{CDCl}_{3}$ ): $\delta 141.0$, 139.3, 131.6, 123.5, 117.6, 116.0, 114.8, 108.4, 108.2, 105.9, 103.7, 102.7, 38.1, 37.9, 36.0, 35.7, 30.4 and 28.0; LCMS m/z Calcd. for $\mathrm{C}_{18} \mathrm{H}_{22} \mathrm{~N}_{3}(\mathrm{M}+\mathrm{H}) 280$, Found 280; Elemental analysis: Calcd. C: 77.38; H: 7.58; N: 15.04, Found C: 77.31; H: 7.62; N: 15.12.

Method - B: To a solution of of hexane-2,5-dione $(1 \mathrm{~mL}, 8.7 \mathrm{mmol})$ in $4 \mathrm{ml}$ of boiling water, under $\mathrm{N}_{2}$ atmosphere, $37 \%$ aqueous $\mathrm{HCl}(150 \mu \mathrm{L}, 1.7 \mathrm{mmol})$ was added, followed by drop-wise addition of pyrrole $(2.4 \mathrm{~mL}, 35 \mathrm{mmol})$. After refluxing for $45 \mathrm{~min}$ the suspension was left to cool and then neutralized with saturated $\mathrm{NaHCO}_{3}$. The compound was extracted with ethyl acetate, dried with anhydrous $\mathrm{Na}_{2} \mathrm{SO}_{4}$ and concentrated under reduced pressure. The crude product was purified by silica gel chromatography to yield $0.98 \mathrm{~g}(42 \%)$ of 7 as white solid.

$2.1 \mathrm{~b} 2,2$ ',2",2"'-(Heptane-2,2,6,6-tetrayl)tetrakis (1H-pyrrole) (4): Method - A: Pyrrole $(5.4 \mathrm{~mL}$, $80 \mathrm{mmol}$ ) and 2,6-heptanedione (500 $\mathrm{mg}, 4 \mathrm{mmol}$ ) were mixed together and under $\mathrm{N}_{2}$ atmosphere TFA $(60 \mu \mathrm{L}$, $0.8 \mathrm{mmol}$ ) was added. The reaction mixture was stirred for $12 \mathrm{~h}$ at room temperature and was quenched by 
adding excess triethylamine. The excess pyrrole was removed by rotary evaporator under reduced pressure. The resultant mixture was purified by silica gel chromatography using dichloromethane as eluent. Evaporation of the eluent and recrystallization from methanol resulted the desired product $\mathbf{4}$ as white solid (417 mg, 30\%), mp $148-150{ }^{\circ} \mathrm{C} ;{ }^{1} \mathrm{H}$ NMR $(400 \mathrm{MHz}$, $\mathrm{CDCl}_{3}$ ): $\delta 7.69$ (brs, $4 \mathrm{H}, \mathrm{NH}$ ), 6.60 (s, 4H, $\left.\alpha-\mathrm{CH}\right), 6.12$ (s, $4 \mathrm{H}, \beta-\mathrm{CH}), 6.00(\mathrm{~s}, 4 \mathrm{H}, \beta-\mathrm{CH}), 1.88(\mathrm{t}, 4 \mathrm{H}, \mathrm{J}=$ $\left.8 \mathrm{~Hz}, \mathrm{CH}_{2}\right), 1.49\left(\mathrm{~s}, 6 \mathrm{H}, \mathrm{CH}_{3}\right), 1.17\left(\mathrm{~m}, 2 \mathrm{H}, \mathrm{CH}_{2}\right) \cdot{ }^{13} \mathrm{C}$ NMR $\left(400 \mathrm{MHz}, \mathrm{CDCl}_{3}\right): \delta 138.23,116.96,107.65$, 104.52, 41.45, 39.03, 26.40, 19.40. LCMS m/z Calcd. for $\mathrm{C}_{23} \mathrm{H}_{28} \mathrm{~N}_{4}\left(\mathrm{M}^{+}\right)$360, Found 360; Elemental analysis: Calcd. C: 76.63; H: 7.83; N: 15.54, Found C: 76.63; H: 7.84; N: 15.87.

2.1c 2,2',2",2"'-(Nonane-2,2,8,8-tetrayl)tetrakis (1H-pyrrole) (5): Method - A: Pyrrole $(4.5 \mathrm{~mL}$, $64 \mathrm{mmol}$ ) and nonane-2,8-dione $(500 \mathrm{mg}, 3.2 \mathrm{mmol})$ were mixed together and under $\mathrm{N}_{2}$ atmosphere TFA ( $47 \mu \mathrm{L}, 0.6 \mathrm{mmol})$ was added. The reaction mixture was stirred for $12 \mathrm{~h}$ at room temperature and was quenched by adding excess triethylamine. The excess pyrrole was removed by rotary evaporator under reduced pressure. The resultant mixture was purified by silica gel chromatography using dichloromethane as eluent. Evaporation of the eluent and recrystallization from methanol resulted the desired product $\mathbf{5}$ as white solid (700 mg, 57\%), mp 168-170 ${ }^{\circ} \mathrm{C} ;{ }^{1} \mathrm{H}$ NMR $\left(400 \mathrm{MHz}, \mathrm{CDCl}_{3}\right): \delta 7.72(\mathrm{~s}, 4 \mathrm{H}, \mathrm{NH}), 6.60(\mathrm{~s}, 4 \mathrm{H}$, $\alpha-\mathrm{CH}), 6.12(\mathrm{~m}, 4 \mathrm{H}, \beta-\mathrm{CH}), 6.04(\mathrm{t}, 4 \mathrm{H}, \mathrm{J}=8 \mathrm{~Hz}, \beta-$ $\mathrm{CH}), 1.87\left(\mathrm{~m}, 4 \mathrm{H}, \mathrm{CH}_{2}\right), 1.55\left(\mathrm{~s}, 6 \mathrm{H}, \mathrm{CH}_{3}\right), 1.33-1.20$ $\left(\mathrm{m}, 6 \mathrm{H}, \mathrm{CH}_{2}\right) .{ }^{13} \mathrm{C} \mathrm{NMR}\left(400 \mathrm{MHz}, \mathrm{CDCl}_{3}\right): \delta 138.18$, $116.86,107.69,104.46,41.22,39.05,30.50,26.23$, 24.38. LCMS m/z Calcd. for $\mathrm{C}_{25} \mathrm{H}_{33} \mathrm{~N}_{4}(\mathrm{M}+\mathrm{H}) 389$, Found 389; Elemental analysis: Calcd. C: 77.28; H: 8.30; N: 14.42, Found C: 77.45; H: 8.28; N: 14.29.

\section{1d 2,2',2",2"'-(Undecane-2,2,10,10-tetrayl)} tetrakis(1H-pyrrole) (6): Method - A: Pyrrole $(3.8 \mathrm{~mL}, 54 \mathrm{mmol})$ and undecane-2,10-dione $(500 \mathrm{mg}$, $2.7 \mathrm{mmol}$ ) were mixed together and under $\mathrm{N}_{2}$ atmosphere TFA ( $40 \mu \mathrm{L}, 0.5 \mathrm{mmol})$ was added. The reaction mixture was stirred for $12 \mathrm{~h}$ at room temperature and was quenched by adding excess triethylamine. The excess pyrrole was removed by rotary evaporator under reduced pressure. The resultant mixture was purified by silica gel chromatography using dichloromethane as eluent. Evaporation of the eluent and recrystallization from methanol resulted the desired product $\mathbf{6}$ as white solid (620 mg, 55\%), mp $140-142^{\circ} \mathrm{C} ;{ }^{1} \mathrm{H}$ NMR $\left(400 \mathrm{MHz}, \mathrm{CDCl}_{3}\right): \delta 7.73(\mathrm{~s}, 4 \mathrm{H}, \mathrm{NH}), 6.63(\mathrm{~m}, 4 \mathrm{H}$, $\alpha$-CH), 6.15 (m, $4 \mathrm{H}, \beta-\mathrm{CH}), 6.09$ (m, $4 \mathrm{H}, \beta-\mathrm{CH}), 1.93$ $\left(\mathrm{m}, 4 \mathrm{H}, \mathrm{CH}_{2}\right), 1.57\left(\mathrm{~m}, 8 \mathrm{H}, \mathrm{CH}_{2}\right), 1.36-1.23(\mathrm{~m}, 2 \mathrm{H}$, $\left.\mathrm{CH}_{2}\right), 1.20\left(\mathrm{~s}, 6 \mathrm{H}, \mathrm{CH}_{3}\right) \cdot{ }^{13} \mathrm{C} \mathrm{NMR}\left(400 \mathrm{MHz}, \mathrm{CDCl}_{3}\right)$ : $\delta 138.24,116.84,107.64,104.42,41.27,39.05,30.06$, 29.69, 26.55, 26.29, 26.21, 24.40. LCMS m/z Calcd. for $\mathrm{C}_{27} \mathrm{H}_{37} \mathrm{~N}_{4}(\mathrm{M}+\mathrm{H})$ 417, Found 417; Elemental analysis: Calcd. C: 77.84; H: 8.71; N: 13.45, Found C: 77.89; H: 8.65; N: 13.68 .

\section{Results and discussion}

The reaction of 2,5-hexanedione $(\mathrm{N}=2)$ with pyrrole under slightly modified Lindsay method (condition A) and aqueous method (condition B) were undertaken; after regular work-up condition A led to formation of products showing many spots in TLC and hence separation was very difficult. However, method B resulted in the formation of a highly unsymmetrical compound 7 instead of the desired bisDPM 3, showing three different type of $\mathrm{NH}$ peaks $7.88,7.79$ and $7.62 \mathrm{ppm}$ and five peaks for the pyrrole protons in ${ }^{1} \mathrm{H}$ NMR (see figure 1) and also the observed mass spectrum $(\mathrm{m} / \mathrm{z}$ 280) did not match with the desired product ( $\mathrm{m} / \mathrm{z} 346)$. These results, confirmed that the desired bisDPM has not formed. To resolve the exact structure of the compound, a single crystal was grown by slow evaporation of dichloromethane and hexane mixture of the compound and the solid state structure obtained by X-ray diffraction, revealed the occurrence of ring annulation, like in the case of acetylacetone but the linking mode is different as depicted in figure $2(42 \%$, table 1, entry 2). Here the ring annulation resulted in the formation of a 4,5,6,7-tetrahydroindole ring, whose 4- and 7- positions were directly linked to the $\alpha$ - position of two pyrrole moieties. In 7, the two pyrrole rings are located on the either side of the plane of the tetrahydroindole moiety, unlike 2 , where the two pyrrole units are located on the same side of the pyrrolizine unit. ${ }^{8}$ The structure now could easily explain the origin of three types of NHs in ${ }^{1} \mathrm{H}$ NMR (7.88, 7.79 and $\left.7.62 \mathrm{ppm}\right)$ along

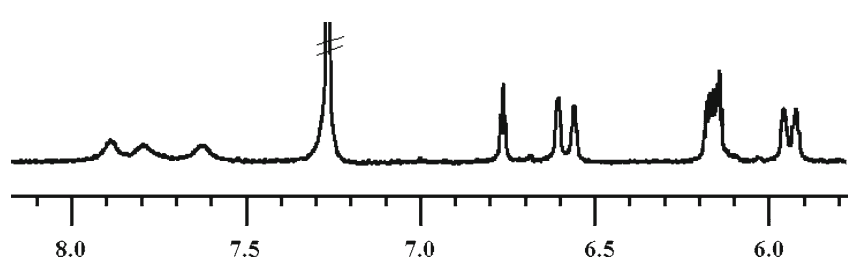

Figure 1. Selected portion of ${ }^{1} \mathrm{H} \mathrm{NMR}$ of $7\left(\right.$ in $\left.\mathrm{CDCl}_{3}\right)$. 


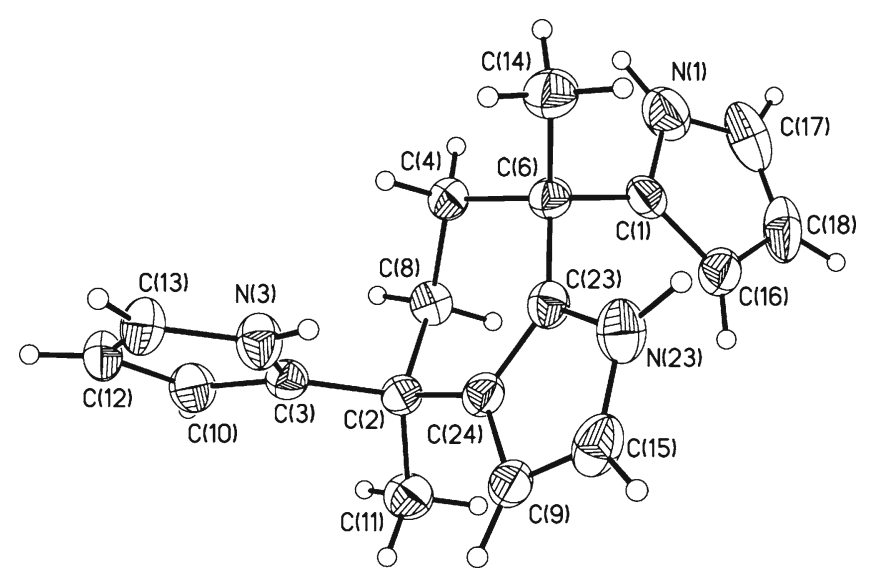

Figure 2. ORTEP diagram of 7, with the displacement ellipsoids drawn at the $35 \%$ probability level. Crystal data: $\mathrm{C}_{18} \mathrm{H}_{21} \mathrm{~N}_{3}, \mathrm{M}=279.38$, monoclinic, $a=6.303(3) \AA, b=$

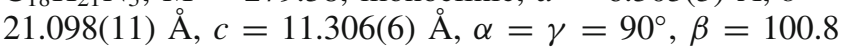
(9) ${ }^{\circ}, V=1476.7$ (13) $\AA^{3}, T=298 \mathrm{~K}$, space group $\mathrm{P} 2(1) / \mathrm{n}$, $Z=4, \mu=0.076 \mathrm{~mm}^{-1}, 2888$ reflections collected, 1447 unique $\left(R_{i n t}=0.0773\right)$, used for direct methods structure determination and full matrix least-squares refinement. The final $w R\left(F^{2}\right)$ was 0.1742 (for all reflections).

with other peaks at $6.75,6.60 \mathrm{ppm}$ (for the pyrrole $\alpha$ $\mathrm{Hs}$ ), 6.55, 6.15, $5.94 \mathrm{ppm}$ (for the pyrrole $\beta$-Hs), 1.91$1.75 \mathrm{ppm}$ (for the methylene Hs of tetrahydronindole ring), $1.62 \mathrm{ppm}$ (for the methyl $\mathrm{Hs}$ ) and further mass data also comply with the new structure. The comparison of TLC of this compound with the earlier mixture obtained via method A, showed the formation of 7 as one of the components. However, purification of the desired product was very difficult. We tried to optimize the conditions of method A, by varying the time, quantity of acid catalyst (TFA) and also equivalents of pyrrole. (1) Longer reaction time (12 h) led to increase of yield up to $50 \%$ (table 1, entry 1 ) and the product could be isolated very easily by column chromatography,

Table 1. Product of reactions proposed via scheme 2.

\begin{tabular}{llccc}
\hline & \multicolumn{1}{c}{ Diketones } & Conditions & Product & Yield \% \\
\hline 1 & Hexan-2,5dione & A & $\mathbf{7}$ & 50 \\
2 & Hexan2,5dione & B & 7 & 42 \\
3 & 2,6-Heptadione & A & $\mathbf{4}$ & 30 \\
4 & 2,6-Heptadione & B & & - \\
5 & 2,8-Heptadione & A & $\mathbf{5}$ & 57 \\
6 & 2,8-Heptadione & B & & - \\
7 & 2,10-Heptadione & A & $\mathbf{6}$ & 55 \\
8 & 2,10-Heptadione & B & & - \\
\hline
\end{tabular}

Condition A: Pyrrole (20 equiv.), TFA (0.2 equiv.), r.t., 12 h.; condition B: Pyrrole (4 equiv.),

conc. $\mathrm{HCl}(0.2$ equiv. $), \mathrm{H}_{2} \mathrm{O}, 90^{\circ} \mathrm{C}, 45 \mathrm{~min}$ which led us to conclude that the unidentified product either is undergoing interconversion (if it is an intermediate) or decomposition under the reaction condition. The obtained product was a mixture of diastereomers, $\left({ }^{13} \mathrm{C}\right.$ NMR, figure 3 , top) from which only one diastereomer could be selectively crystallized out (in $44 \%$ yield, figure 3 , bottom) by dissolving the product in a minimum amount of chloroform followed by addition of few drops of hexane and keeping the resultant solution in refrigerator for overnight. The separated diastereomer is stable even in atmospheric conditions, whereas, the mixture tends to get coloured in a couple of days under atmospheric conditions and slowly led to degradation. Also, we could resolve only two enantiomers in chiral HPLC, whereas the remaining two could not be achieved (see Supplementary data). (2) By increasing the concentration of acid catalyst (up to 1 equiv.) the reaction completed in lesser time $(4 \mathrm{~h})$, however, the yield decreases to $44 \%$. (3) Increasing the amount of pyrrole up to 40 equiv. only results in a marginal increase in yield (51\%). Further increase in quantity of pyrrole (100 equiv.), did not alter the yield appreciably $(50 \%)$. As ketone groups are less reactive compared to aldehydes, therefore the formation of larger oligopyrromethanes are less probable in our case, hence we presume, increase in pyrrole content did not alter the yield significantly. The proposed mechanism for the formation of 7 (figure 4) proceeds via the formation of DPM through the general acid catalysed condensation of one of the carbonyl group of 2,5-hexanedione to form $\mathbf{8}$, which again undergoes condensation with another pyrrole molecule to form the hydroxyl derivative 9. The protonated hydroxyl derivative 10, undergoes the loss of a water molecule to form the carbonium ion 11, which undergoes intramolecular nucleophilic substitution to form the ring annulated product 12, which upon the subsequent loss of a proton, results in the formation of tetrahydroindole bridged bipyrrole 7 .

The reaction of 2,6-heptanedione ${ }^{9}$ with pyrrole finally produced the desired divergent bisDPM 4, via method A, in $30 \%$ yield (table 1, entry 3 ). The reaction mixture was purified on a silica gel column to obtain the desired product as the first major fraction (the first moving minor fraction, a brown viscous oil was unstable and hence could not be characterized) and was followed by a small amount of mono-condensed product. However, method B produced many close lying spots in TLC along with a little amount of product where separation becomes very difficult. Product $\mathbf{4}$ was characterized by ${ }^{1} \mathrm{H}$ and ${ }^{13} \mathrm{C}$ NMR (shows the symmetric nature of the bisDPM) and mass spectral data and the final confirmation came from the solid state structure, obtained 


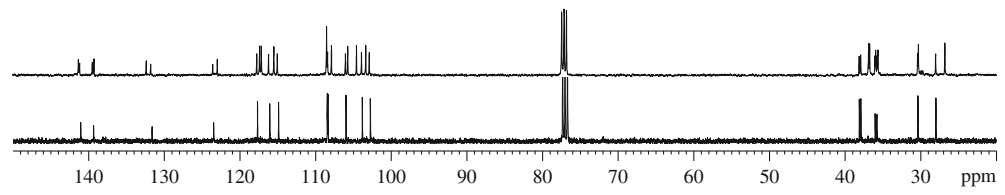

Figure 3. ${ }^{13} \mathrm{CNMR}$ of 7 in $\mathrm{CDCl}_{3}$ : top - mixture of diastereomers; bottom - pure diastereomer isolated by crystallization.

from a single crystal grown by slow evaporation of a chloroform solution of the desired compound via X-ray diffraction (figure 5). The divergent nature of the bisDPM could be observed from the structure which shows that both the DPM units reside away from each other, linked via the propylene bridge and they are almost orthogonal to each other. Again, a higher concentration of pyrrole (100 equiv.) results in slight increase in yield $(34 \%)$, however the presence of a very minor quantity of mono condensed product still observed (only detected in mass spectrum of the crude compound). Further, we carried out the reactions of 2,8-nonanedione and 2,10-undecanedione ${ }^{10}$ with pyrrole under the similar conditions and obtained the desired bisDPMs 5 and 6 in $57 \%$ (table 1, entry 5) and $55 \%$ (table 1 , entry 7) respectively, following method A. The products were easily purified from the reaction mixtures by column chromatography, which also contained a trace amount of mono condensed DPM derivative (from mass spectra). Both the compounds were characterized by ${ }^{1} \mathrm{H}$ and ${ }^{13} \mathrm{C}$ NMR and mass spectral data. Also solid state structure of $\mathbf{5}$ could be obtained by single crystal XRD by growing crystals from dichloromethane solution through slow evaporation (figure 6), which again confirms the divergent nature of the dipyrromethane units in this type of bisDPMs like 4. Again higher concentration of pyrrole (100 equiv.) had very marginal effect on the yield of the products (5: $59 \%$ and 6: 54\%) and still the presence of very minor quantity of mono condensed product could not be eradicated. Method B, once again did not result in the formation of any isolable products in either cases (table 1, entry 6 and 8). The failure of Method B to produce any isolable desirable bisDPMs, may be attributed to the harsh reaction condition, i.e., high temperature and strong acid catalyst (aq. $\mathrm{HCl}$ ), playing a role in the decomposition of the product along with the intermediates formed (if any). This may be one of the reason for the limited number of carbonyl compounds being tested in the original reference 5 . These results show that in spite of being a environmentally benign pathway, method B is not as versatile as the Lindsay's type method (method A), which could be

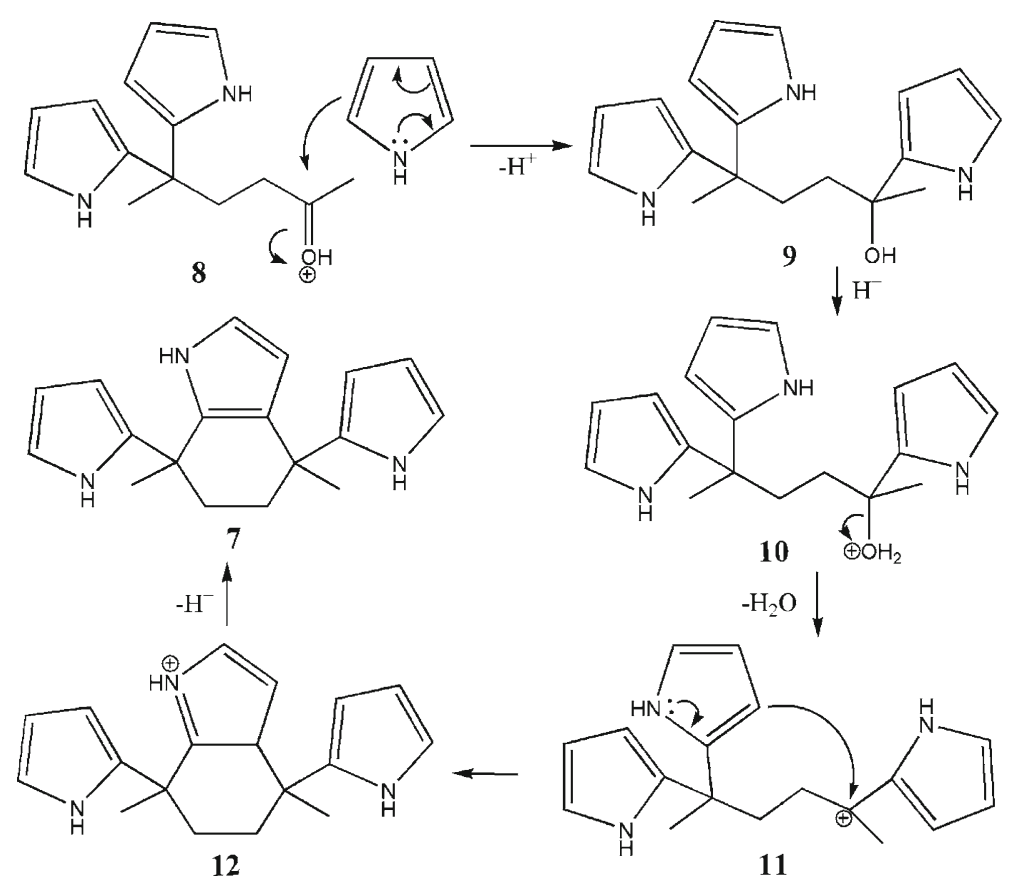

Figure 4. Proposed mechanism for the formation of 7. 


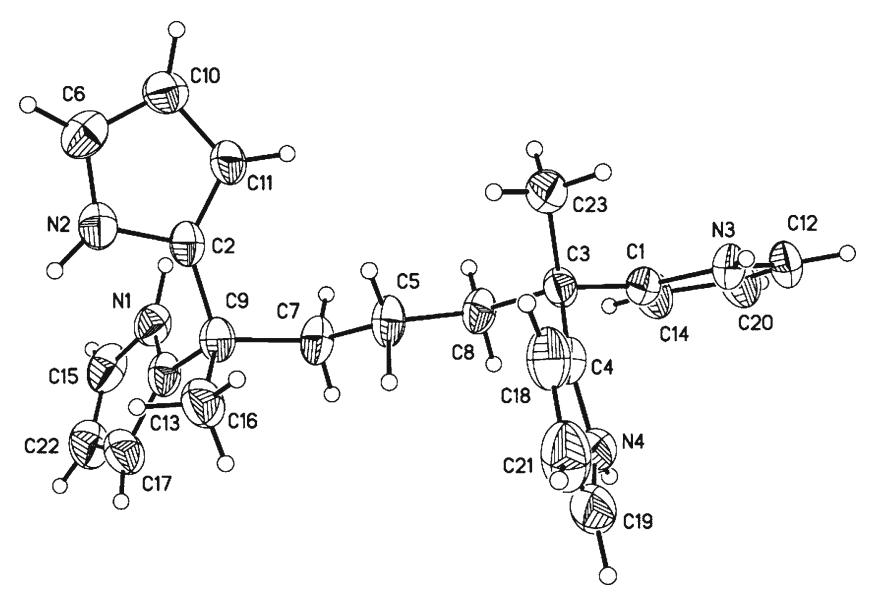

Figure 5. ORTEP diagram of 4, with the displacement ellipsoids drawn at the $35 \%$ probability level. Crystal data: $\mathrm{C}_{23} \mathrm{H}_{28} \mathrm{~N}_{4}, \mathrm{M}=360.49$, monoclinic, $a=10.558(3) \AA, b=$ 14.448(5) $\AA, c=13.595(4) \AA, \alpha=\gamma=90^{\circ}, \beta=97.92$ (7) ${ }^{\circ}, V=2053.9(11) \AA^{3}, T=298 \mathrm{~K}$, space group P2(1)/n, $Z=4, \mu=0.070 \mathrm{~mm}^{-1}, 3641$ reflections collected, 1657 unique $\left(R_{\text {int }}=0.09\right)$, used for direct methods structure determination and full matrix least-squares refinement. The final $w R\left(F^{2}\right)$ was 0.2417 (for all reflections).

easily modulated by changing the quantity of acid catalyst, time and quantity of pyrrole to obtain the desired product. Moreover, in case of the ketones, owing to their lesser reactivity, very large excess of pyrrole is not warranted.

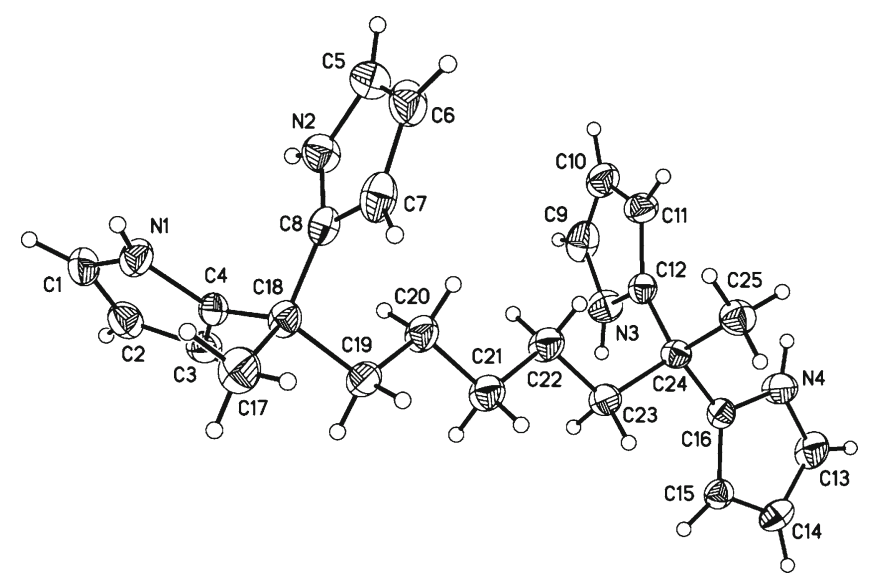

Figure 6. ORTEP diagram of 5, with the displacement ellipsoids drawn at the $35 \%$ probability level. Crystal data: $\mathrm{C}_{25} \mathrm{H}_{32} \mathrm{~N}_{4}, \mathrm{M}=388.55$, monoclinic, $a=8.874(2) \AA, b=$ 28.503(6) $\AA, c=8.762(19) \AA, \alpha=\gamma=90^{\circ}, \beta=98.879$ $(4)^{\circ}, V=2189.8(8) \AA^{3}, T=298 \mathrm{~K}$, space group P2(1)/c, $Z=4, \mu=0.070 \mathrm{~mm}^{-1}, 5285$ reflections collected, 2590 unique $\left(R_{\text {int }}=0.11\right)$, used for direct methods structure determination and full matrix least-squares refinement. The final $w R\left(F^{2}\right)$ was 0.2092 (for all reflections).

\section{Conclusions}

Reaction of diketones, in particular the alkyl chain bridged ones with pyrrole under acidic conditions were explored in detail following two methods (A and B). 2,6-Hexadione led to the formation of ring annulated product like acetylacetone, ${ }^{8 \mathrm{a}}$ with a different mode of annulation, by a more favourable nucleophilic substitution reaction. The selective formation of $\mathbf{7}$, and the asymmetric nature of the three pyrrole units in the molecule may find use as an interesting building block in porphyrinoid chemistry. ${ }^{11}$ Further increase in the distance between the two carbonyl groups to three carbon chain (propylene unit) only resulted in the formation of the desired divergent bisdipyrromethane and the trend continued upon increasing the length of the spacer to five or seven carbon units. 4-6 can be used as building blocks towards the synthesis of biscalixpyrroles and other related macrocycles. Efforts are presently underway in this direction in our laboratory.

Crystallographic data (excluding the structure factor) for structures $\mathbf{4 , 5}$ and $\mathbf{7}$ in this paper have been deposited in the Cambridge Crystallographic Data Centre as supplementary publication number CCDC $748778-748780$. Copies of the data can be obtained free of charge on application to CCDC, 12 Union Road, Cambridge CB21EZ, UK (Fax: +44(0)-1223-336033 or e-mail: deposit@ccdc.cam.ac.uk).

\section{Supplementary information}

The electronic supporting information can be seen in www.ias.ac.in/chemsci.

\section{Acknowledgements}

This work was supported by the Department of Science and Technology (DST), India (Grant no. SR/S1/IC20/2007). SPM thanks the Council of Scientific and Industrial Research (CSIR), New Delhi, India for the Senior Research Fellowship.

\section{References}

1. Lindsay J S, 2000 In The Porphyrin Handbook; K M Kadish, K M Smith, R Guilard, (eds.); San Diego: Academic Press Vol. 1 pp 45-118 and references cited therein

2. (a) Sessler J L, Anzenbacher Jr. P, Jursikova K, Miyaji $\mathrm{H}$, Genge J W, Tvermoes N A, Allen W E, Shriver J A, Gale P A, Kral V. 1998 Pure and Appl. Chem. 702401 and references cited therein; (b) Benech J M, Bonomo L, Solari E, Scopelliti R, Floriani C. 
1999 Angew. Chem. Int. Ed. 38 1957; (c) Kral V, Sessler J L, Zimmerman R S, Seidel D, Lynch V, Andrioletti B. 2000 Angew. Chem. Int. Ed. 39 1055; (d) Dolensky B, Kroulik J, Kral V, Sessler J L, Dvorykova H, Boury P, Bernatkova M, Bucher C, Lynch V. 2004 J. Am. Chem. Soc. 126 13714; (e) Bernatkova M, Andrioletti B, Kral V, Rose E, Vaissermann J. 2004 J. Org. Chem. 69 8140; (f) Jha S C, Lorch M, Lewis R A, Archibald S J, Boyle R W. 2007 Org. Biomol. Chem. 51970

3. (a) Yoon D W, Hwang H, Lee C H. 2002 Angew. Chem. Int. Ed. 41 1757; (b) Lee C H, Na H K, Yoon D W, Won D H, Cho W S, Lynch V M, Shevchuk S V, Sessler J L. 2003 J. Am. Chem. Soc. 125 7301; (c) Panda P K, Lee C H. 2004 Org. Lett. 6 671; (d) Panda P K, Lee C H. 2005 J. Org. Chem. 70 3148; (e) Miyaji H, Kim H K, Sim E K, Lee C K, Cho W S, Sessler J L, Lee C H. 2005 J. Am. Chem. Soc. 127 12510; (f) Lee C H, Lee J S, Na H K, Yoon D W, Miyaji H, Cho W S, Sessler J L. 2005 J. Org. Chem. 70 2067; (g) Samanta R, Mahanta S P, Chaudhuri S, Panda P K, Narahari A 2011 Inorganica Chim. Acta 372281

4. (a) Lee C H, Lindsay J S. 1994 Tetrahedron 50 11427; (b) Littler B J, Miller M A, Hung C H, Wagner R W, O'Shea D F, Boyle P D, Lindsey J S. 1999 J. Org. Chem. 64 1391; (c) Gryko D, Lindsey J S. 2000 J.Org. Chem.
65 2249; (d) Laha J K, Dhanalekshmi S, Taniguchi M, Ambroise A, Lindsey J S. 2003 Org. Proc. Res. and Dev. 7799

5. Sobral A J F N, Rebanda N G C L, Silva M D, Lampreia S H, Silva M R, Beja A M, Paixao J A, Gonsalves A M D. 2003 Tetrahedron Lett. 443971

6. (a) Khoury R G, Jaquinod L, Smith K M. 1997 Chem. Commun. 1057; (b) Sato W, Miyaji H, Sessler J L. 2000 Tetrahedron Lett. 41 6731; (c) Nakano A, Osuka A, Yamazaki I, Yamazaki T, Nishimura Y. 1998 Angew. Chem. Int. Ed. 373023

7. (a) Arumugam N, Chung W Y, Lee S W, Lee C H. 2001 Bull. Korean Chem. Soc. 22 932; (b) Renic M, Basaric N, Mlinaric-Majerski K. 2007 Tetrahedron Lett. 487873

8. (a) Mahanta S P, Panda P K. 2009 Tetrahedron Lett. 50 890; (b) Mahanta S P, Sathish Kumar B, Panda P K 2011 Chem. Commun. 474496

9. Overberger C G, Thomas B G Jr, Chibnik S, Huang P, Monagle J J. 1952 J. Am. Chem. Soc. 743290

10. (a) Yamashita M, Matsumiya K, Morimoto H, Seumitsu R. 1989 Bull. Chem. Soc. Jpn. 62 1668; (b) Bai X, Eliel L E. 1991 J. Org. Chem. 56 2087; (c) Hatt H H. 1936 Org. Synth. 1622

11. Miyaji H, Hong S J, Jeong S D, Yoon D W, Na H K, Hong J, Ham S, Sessler J L, Lee C H. 2007 Angew. Chem. Int. Ed. 462508 